\title{
OCENA STABILNOŚCI POSTURALNEJ U OSÓB POWYŻEJ 65. R.Ż. Z WYKORZYSTANIEM PLATFORMY BALANSOWEJ
}

\section{ANALYZE POSTURAL STABILITY IN POPULATION ABOVE 65 YEARS OLD USING PLATFORM BALANCE}

\author{
Marzena Mańdziuk, Blanka Kaszuba, Marlena Krawczyk-Suszek \\ Katedra Fizjoterapii, Wydział Medyczny, Wyższa Szkoła Informatyki i Zarządzania w Rzeszowie
}

DOI: https://doi.org/10.20883/ppnoz.2019.19

\section{STRESZCZENIE}

Wstęp. Utrzymywanie równowagi zarówno statycznej, jak i dynamicznej zależy od prawidłowego funkcjonowania systemu kontroli postawy, utrzymującego rzut środka ciężkości ciała (COP, center of feet pressure) w obrębie pola podparcia oraz zdolnego przeciwdziałá́ zewnętrznym siłom mogącym destabilizować postawę. Badanie za pomocą platformy stabilometrycznej Cosmogamma by Emildue dostarcza cennych i znaczących klinicznie danych o szerokim spektrum zastosowania.

Cel pracy. Celem pracy była analiza wybranych parametrów przemieszczania środka nacisku stóp na podłoże, przy użyciu komputerowej platformy balansowej jako metody badania zdolności utrzymania równowagi.

Materiał i metody. Badaną grupę stanowiło 27 podopiecznych Domu Pomocy Społecznej w Rzeszowie. Metodami badawczymi były: ankieta, stanowiąca kryterium do drugiej części badania, które przeprowadzono z wykorzystaniem platformy Cosmogamma by Emildue. Badanie składało się z trzech 60-sekundowych prób:

I próba: $z$ otwartymi oczami - po czym nastąpiła przerwa 15 minut;

II próba: $z$ otwartymi oczami - po czym nastąpiła przerwa 60 sekund;

III próba: z zamkniętymi oczami.

Wyniki. Analiza wszystkich obserwowanych parametrów wykazała, że w przypadku zdecydowanej większości analizowanych danych największymi wartościami parametrów charakteryzowała się próba z zamkniętymi oczami. Wystąpiły także różnice pomiędzy dwoma próbami z otwartymi oczami - II próba charakteryzowała się mniejszymi wartościami analizowanych parametrów. Wykazano, że zachodzą istotne statystycznie zależności prędkości w danej płaszczyźnie od odchylenia w tej płaszczyźnie, a także wieku od długości ścieżki. Ponadto zaobserwowano, że wartości obserwowanych parametrów nie zależą od płci.

Wnioski. Wraz z wiekiem spada zdolność utrzymania równowagi w pozycji stojącej. Płeć nie ma istotnego znaczenia w ocenie poziomu równowagi. Wyłączenie kontroli wzroku wpływa niekorzystnie na stabilność posturalną. Istotnym czynnikiem wpływającym na poprawę zdolności utrzymywania równowagi jest element treningu.

Słowa kluczowe: równowaga fizyczna, ryzyko upadków, Cosmogamma.

ABSTRACT

Introduction. Maintaining balance, both static and dynamic which depends on the proper functioning of the postural control system persisting a center of gravity (COP center of feet pressure) within a field support and able to counteract the external forces that could destabilize attitude. The study via the platform stabilometric Cosmogamma by Emildue provides valuable and clinically relevant data on a wide range of applications.

Aim. The aim of the study was to analyze selected parameters of pressure center moving feet on the ground, using computerized balance platform as a method of testing the ability to maintain a balance.

Material and methods. The study group consisted of 27 charges Nursing Home in Rzeszow. Research methods were interview, which is a criterion for the second part of the study, which was conducted using the platform Cosmogamma by Emildue. The study consisted of three 60-second samples:

The first test: with open eyes - and then there was a break 15 minutes;

Second test: with open eyes - and then there was a pause 60 seconds;

Third test: with eyes closed.

Results. The analysis of all the parameters observed showed that the vast majority of data analyzed, the highest values of parameters characterized by the test with eyes closed. There were also differences between the two samples with eyes open - second test was characterized by lower values of the analyzed parameters.

It has been shown that there are statistically significant depending on the speed of the plane of deflection in this plane, and the age of the length of the path. Furthermore, it was observed that the values of the parameters observed are not dependent on sex.

Conclusions. With age, decreasing ability to maintain balance while standing. Gender is not significant in assessing the level of equilibrium. Disable checking eyesight adversely affects the postural stability. An important factor for improving the ability to keep balance is part of the training.

Keywords: balance, risk of falls, Cosmogamma. 


\section{Wstęp}

Inwolucyjne zmiany zachodzące w organizmie wraz z wiekiem wpływają na zmniejszenie sprawności fizycznej. Upośledzenie funkcji układu ruchu koreluje z zaburzoną stabilnością posturalną. Zmiany dotyczące narządów zmysłów biorących udział w kontroli postawy: wzroku, słuchu, równowagi, czucia powierzchownego i głębokiego, a także zmiany w układzie nerwowym i mięśniowo-szkieletowym znacznie zwiększają ryzyko upadków i urazów u osób powyżej 60 roku życia [1-2]. Zaburzenia orientacji przestrzennej są następstwem zarówno tzw. wychwiań, jak i braku wyobrażenia i uwzględnienia składowych mechaniki ruchów dowolnych. Wskutek nieprawidłowego przewidywania ruchu, zmniejszonej precyzji i koordynacji dochodzi do upadków, których następstwa stanowią bardzo poważny problem medyczny, społeczny i ekonomiczny [3]. Utrzymywanie równowagi, zarówno statycznej, jak i dynamicznej, zależy od prawidłowego funkcjonowania systemu kontroli postawy utrzymującego rzut środka ciężkości ciała (COP, center of feet pressure) w obrębie pola podparcia oraz zdolnego przeciwdziałać zewnętrznym siłom mogącym destabilizować postawę [4-8]. W czasie spokojnego stania obserwuje się pewien zakres odchyleń ciała człowieka od pionu, a kołysanie to uważa się za wskaźnik sprawności systemu kontroli utrzymywania równowagi. Podczas utrzymywania pozycji pionowej kołysanie zwiększa się, kiedy napływ któregoś z bodźców z obwodu zostaje przerwany [9]. Zjawisko to nasila się po 60. roku życia jako wyraz postępującego upośledzenia układu kontroli postawy. Jest ono wówczas silnym, niezależnym czynnikiem ryzyka upadków i wspótistniejących z nimi urazów. Komputerowa platforma balansowa Cosmogamma by Emildue dostarcza cennych informacji na temat zmian poszczególnych parametrów przemieszczania środka nacisku stóp na podłoże [9-12]. Odzwierciedla przemieszczenia działania sił nacisku stóp na powierzchnię platformy równowagi w czasie spokojnego stania. Za pomocą badania możliwa jest analiza kontroli postawy, wykrywanie zaburzeń równowagi i ryzyka upadków [9], monitorowanie wpływu rehabilitacji czy systematycznej aktywności na zdolność utrzymania prawidłowej postawy.

W pracy dokonano analizy przemieszczeń COP $\mathrm{w}$ czasie spokojnego stania obunóż na platformie stabilometrycznej podczas badania z oczami otwartymi, jak również zamkniętymi. Otrzymano cenne informacje dotyczące procesu utrzymania równowagi statycznej zarówno podczas pełnej kontroli wzroku, jak i po jej wyłączeniu.

\section{Cel pracy}

Celem niniejszej pracy była analiza wybranych parametrów przemieszczania środka nacisku stóp na podłoże, przy użyciu komputerowej platformy balansowej jako metody badania stabilności posturalnej w populacji osób powyżej 65. r.z.z.

\section{Materiał i metody}

Badaną grupę stanowiło 27 podopiecznych Domu Pomocy Społecznejw Rzeszowie: 17 kobiet 10 mężczyzn. Kryteriami zakwalifikowania seniorów do badań były: pisemna zgoda na udział w badaniu, wiek powyżej 65 lat, samodzielność w wykonywaniu czynności dnia codziennego, zdolność utrzymania samodzielnie pozycji stojącej, brak w ciągu ostatnich 6 miesięcy złamań i urazów w obrębie kończyny dolnej. $Z$ badań wykluczono osoby, które nie wyraziły zgody na udział w badaniu, z przebytymi incydentami mózgowymi, z niedowładami połowiczymi oraz ze zdiagnozowaną chorobą Parkinsona.

Metodami badawczymi, jakimi posłużono się w pracy, były ankieta, składająca się z 2 części: pierwszej, uwzględniającej podstawowe dane osobowe oraz drugiej, ukazującej informacje na temat aktualnego stanu zdrowia, chorób wspótistniejących, a także przyczyn i skutków upadków. Ankieta była również czynnikiem kwalifikującym seniorów do dalszej części badań.

Kolejnym etapem badania pensjonariuszy rzeszowskiego Domu Pomocy Społecznej było badanie z wykorzystaniem platformy Cosmogamma by Emildue. Spośród 90 chętnych do badań wykluczono 63 osoby, w badaniach wzięło udział 27 seniorów.

Badanie składało się z trzech prób, z których każda trwała 60 sekund.

I próba: z otwartymi oczami - po czym nastąiłła przerwa 15 minut;

II próba: z otwartymi oczami - po czym nastąpiła przerwa 60 sekund;

III próba: z zamkniętymi oczami.

Każdy z rzeszowskich seniorów został szczegółowo poinstruowany o celowości, istocie i metodyce wykonania badania, w czasie którego miał za zadanie zachować pozycję stojącą, wzrok skierowany na wprost, kończyny górne zwieszone swobodnie wzdłuż tułowia. W pomieszczeniu, w którym wykonywano badanie, była cisza, a badani byli skoncentrowani. Podczas wszystkich prób przy każdym seniorze w trakcie badania asekuracyjnie stał terapeuta, drugi terapeuta z kolei obsługiwał sprzęt. 


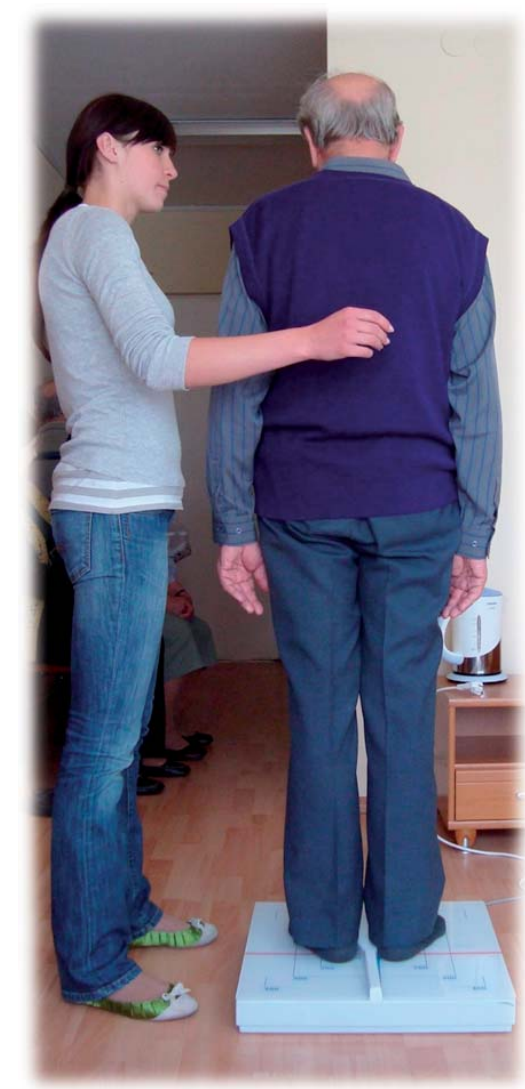

Rycina 1. Badanie przy użyciu platformy stabilometrycznej Cosmogamma

\section{Wyniki}

Badaniem objęto 27 osób w wieku 71-87 lat, 17 kobiet i 10 mężczyzn. Średni wiek badanych wynosił $81,5 \pm 4,39$ roku (Tabela 1).

Tabela 1. Wiek, waga, wzrost badanych

\begin{tabular}{|l|c|c|c|} 
& Średnia & Me & SD \\
\hline Wiek & 81,5 & 82 & 4,39 \\
\hline Waga [kg] & 71 & 72 & 12,37 \\
\hline Wzrost [m] & 1,54 & 1,55 & 0,094 \\
\hline
\end{tabular}

Podczas badania na platformie stabilometrycznej Cosmogamma by Emildue otrzymano następujące parametry: maksymalne odchylenie $(\mathrm{mm})$, długość ścieżki $(\mathrm{mm})$, prędkość boczna $(\mathrm{mm} / \mathrm{s})$, prędkość przednio-tylna $(\mathrm{mm} / \mathrm{s})$, przebywanie w promieniu $13 \mathrm{~mm}, 25 \mathrm{~mm}, 38 \mathrm{~mm}$ i $50 \mathrm{~mm}$, średni punkt obciążenia $(\mathrm{mm})$, średnie odchylenie $(\mathrm{mm})$, główna prędkość $(\mathrm{mm} / \mathrm{s})$, obszar docisku do ścieżki $(\mathrm{cm})$ oraz obszar prędkości $(\mathrm{cm} / \mathrm{s})$.

Analizie statystycznej w programie STATISTICA poddano całkowitą długość ścieżki, maksymalne odchylenie, a także prędkość w płaszczyźnie czołowej i strzałkowej. Dla wszystkich parametrów obliczono wartości podstawowych statystyk opisowych (Tabela 2). Do oceny istotności statystycznej zmian w próbach o oczach otwartych i zamkniętych wykorzystano nieparametryczny test kolejności par Wilcoxona. Ponadto dla zobrazowania zależności między płcią a poszczególnymi parametrami posłużył test U Manna-Withneya. Za poziom istotności przyjęto $p<0,05$.

Tabela 2. Wartości podstawowych statystyk opisowych

\begin{tabular}{|l|c|c|c|c|} 
Zmienna & Próba & Średnia & Me & SD \\
max odchyl - y & I oo & 10,39 & 9,84 & 4,44 \\
& II oo & 9,37 & 7,83 & 5,13 \\
& oz & 12,35 & 8,94 & 9,5 \\
max odchyl - x & I oo & 12,44 & 11,79 & 3,98 \\
& II oo & 12,55 & 11,75 & 5,73 \\
& oz & 12,64 & 11,04 & 4,81 \\
dł. ścieżki & I oo & 459,26 & 438,69 & 117,89 \\
& II oo & 415,75 & 395,81 & 116,36 \\
& oz & 629,31 & 535,34 & 308,7 \\
pr. boczna & I oo & 6,31 & 6,47 & 2,27 \\
& II oo & 5,43 & 4,93 & 1,73 \\
& oz & 7,79 & 7,33 & 4,1 \\
pr. p-tylna & I oo & 11,02 & 10,97 & 3,19 \\
& II oo & 10,08 & 9,23 & 3,43 \\
& oz & 16,37 & 13,4 & 8,93
\end{tabular}

Analiza obserwowanych parametrów wykazała, iż w przypadku wszystkich danych najwyższymi wartościami charakteryzowała się próba o oczach zamkniętych, jednakże tylko w przypadku długości ścieżki różnice te były istotne statystycznie $(p=0,00051)$. Analiza różnic między danymi z prób o oczach otwartych wykazała, spadek wartości większości parametrów w próbie II, przy czym różnice to nie wykazały istotności statycznej. Test kolejności par Wilcoxona wykazał, że zachodzą istotne statystycznie zależności prędkości w danej płaszczyźnie od odchylenia w tej płaszczyźnie (Tabela 3).

Ponadto istotne statystycznie są wyniki zależności wieku od długości ścieżki (Tabela 4) w przypadku wszystkich obserwowanych prób oraz wieku od prędkości przedniotylnej i bocznej (Wykresy 1A, 1B, 2A, 2B). Analizie poddano także wszystkie wartości obserwowanych parametrów w zależności od płci (Tabela 5). W żadnym przypadku test U Manna-Withneya nie wykazał istotnych statystycznie zależności. 
Tabela 3. Zależności prędkości w danej płaszczyźnie od odchylenia w tej płaszczyźnie

\begin{tabular}{|c|c|c|c|c|}
\hline \multirow{2}{*}{ Para zmiennych } & \multicolumn{4}{|c|}{$\begin{array}{l}\text { Test kolejności par Wilcoxona (DPS - stabilność } \\
\text { Zaznaczone wyniki są istotne z p <,05000 }\end{array}$} \\
\hline & $\begin{array}{c}\mathrm{N} \\
\text { ważnych }\end{array}$ & $T$ & Z & poziom $p$ \\
\hline $\begin{array}{l}\text { Max odch(oo)-y } \\
\& \text { Prboczna(oo) }\end{array}$ & 27 & 2,00000 & 4,492675 & 0,000007 \\
\hline $\begin{array}{l}\text { Max odch(oo)-x } \\
\text { \& Pptylna(oo) }\end{array}$ & 27 & 75,00000 & 2,738850 & 0,006166 \\
\hline $\begin{array}{l}\text { Max odch(oz)-y } \\
\& \text { Pboczna(oz) }\end{array}$ & 27 & 20,0000 & 4,06022 & 0,00004 \\
\hline $\begin{array}{l}\text { Max odch(oz)-x } \\
\& \text { Pptylna(oz) }\end{array}$ & 27 & 51,0000 & 3,31545 & 0,00091 \\
\hline
\end{tabular}

Tabela 4. Zależności wieku od długości ścieżki

\begin{tabular}{|c|c|c|c|c|} 
& \multicolumn{5}{|c|}{ Test kolejności par Wilcoxona (DPS-stabilność) } \\
Para zmiennych & \multicolumn{2}{|c|}{ Zaznaczone wyniki są istotne z p <,05000 } \\
& N & T & Z & poziom p \\
Ważnych & & & \\
wiek \&Dł. ścieżki(oo) & 27 & 0,00 & 4,540725 & 0,000006 \\
wiek \&Dł. ścieżki(oo) & 27 & 0,00 & 4,540725 & 0,000006 \\
wiek \&Dł. ścieżki(oz) & 27 & 0,00 & 4,540725 & 0,000006
\end{tabular}

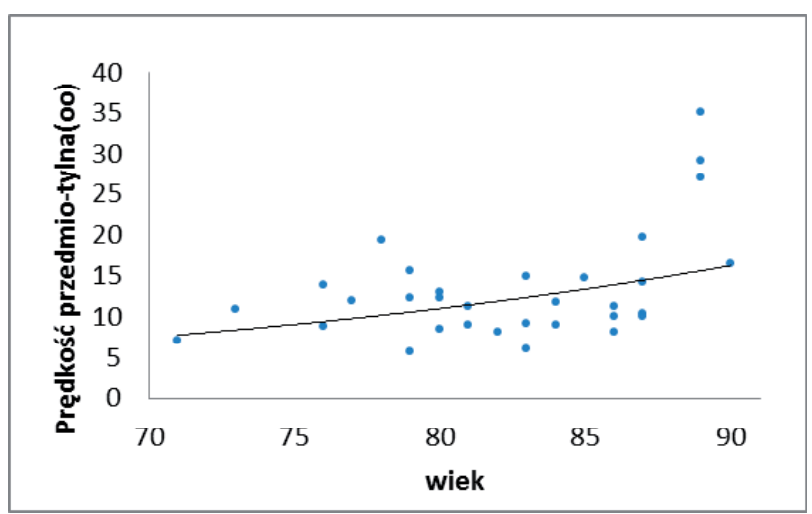

Wykres 1A. Zależność prędkości przednio-tylnej od wieku (oczy otwarte)

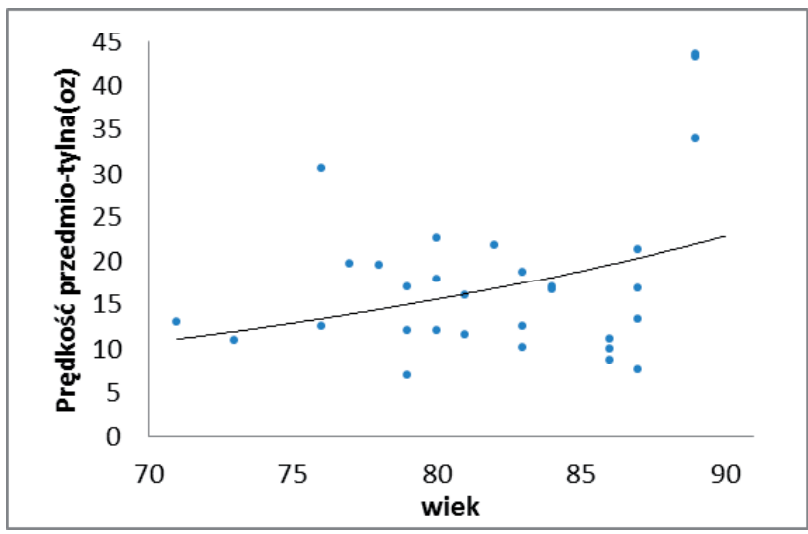

Wykres 1B. Zależność prędkości przednio-tylnej od wieku (oczy zamknięte)

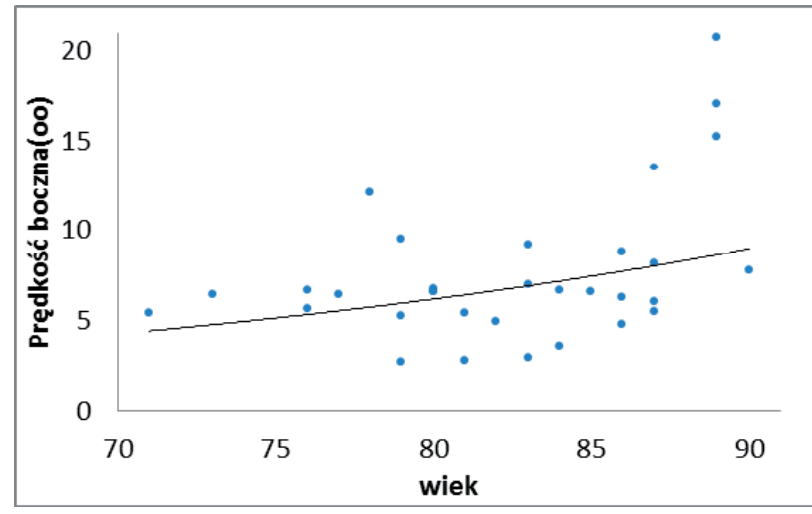

Wykres 2A. Zależność prędkości bocznej od wieku (oczy otwarte)

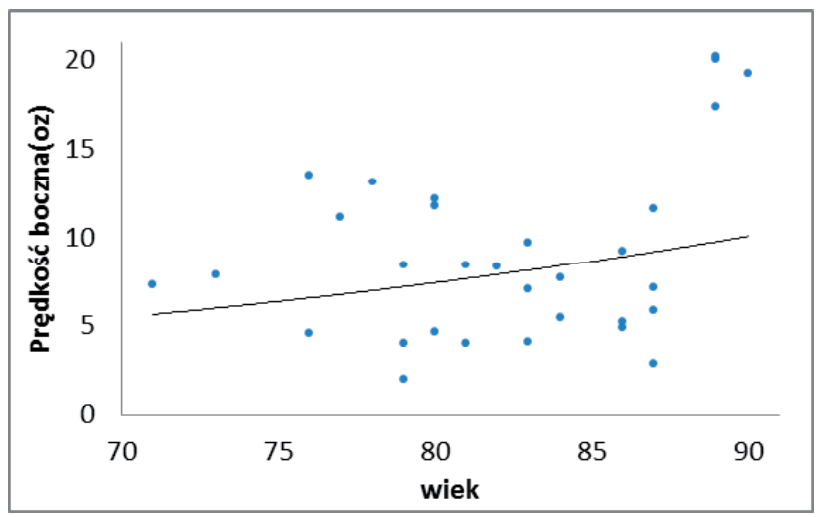

Wykres 2B. Zależność prędkości bocznej od wieku (oczy zamknięte)

Tabela 5. Zależności parametrów od płci

\begin{tabular}{|c|c|c|c|c|c|c|c|}
\hline \multirow{2}{*}{ zmienna } & \multicolumn{7}{|c|}{$\begin{array}{l}\text { Test U Manna-Whitneya (DPS-stabilność) } \\
\text { Wzg.zmienn. płeć } \\
\text { Zaznaczone wyniki są istotne z p <,05000 }\end{array}$} \\
\hline & $\begin{array}{c}\text { Sum.rang } \\
\mathrm{m}\end{array}$ & $\begin{array}{c}\text { Sum.rang } \\
k\end{array}$ & U & Z & poziom $p$ & $\begin{array}{c}\mathrm{Z} \\
\text { popraw. }\end{array}$ & poziom $p$ \\
\hline $\operatorname{Max} \operatorname{odch}(00)-y$ & 78,00000 & 300,0000 & 57,00000 & $-0,349927$ & 0,726394 & $-0,349927$ & 0,726394 \\
\hline Max odch $(00)-x$ & 77,00000 & 301,0000 & 56,00000 & $-0,408248$ & 0,683092 & $-0,408248$ & 0,683092 \\
\hline Prboczna(oo) & 86,00000 & 292,0000 & 61,00000 & 0,116642 & 0,907144 & 0,116731 & 0,907073 \\
\hline Pptylna(oo) & 80,50000 & 297,5000 & 59,50000 & $\mid-0,204124$ & $|0,838257|$ & $\mid-0,204155$ & 0,838232 \\
\hline
\end{tabular}

\section{Dyskusja}

Współczesne społeczeństwo polskie należy do sukcesywnie starzejących się demograficznie, w związku z czym badanie zdolności zachowania równowagi seniorów ma olbrzymie znaczenie. W literaturze można znaleźć liczne testy służące do oceny wielu aspektów koordynacji ruchowej, w tym zdolności zachowania równowagi oraz sprawności motorycznej. Powszechnie stosowanym narzędziem badawczym są testy kliniczne, dostarczające zarówno jakościowych, jak i ilościowych danych. Ich zaletą jest możliwość wielopłaszczyznowej oceny sprawności funkcjonalnej seniorów, uwzględniając niskie koszty, dużą dostępność i łatwość zastosowania. Wśród licznych skal i testów wykorzystywanych do oceny równowagi wyróżnić można skale: Berga, Fullerton Advanced Balance Scale, 
test Tinnettiego, test Up\&Go, Functional Reach Test, Tandem Stance, Walk lub Pivot Test. Ideą tych testów są określone zadania ruchowe, których wynikiem jest najczęściej czas, w jakim badany wykonał próbę, pokonał dystans, lub suma punktów z poszczególnych prób [3-6]. Testy kliniczne w publikacjach medycznych uważane są jednak za metody subiektywne, a ich rzetelność jest uzależniona od umiejętności i doświadczenia zawodowego badającego [7]. W czasopismach medycznych pojawiły się artykuły zwracające uwagę na stopień zadowolenia praktykujących fizjoterapeutów z dostępnych klinicznych metod oceny równowagi [8]. Nie da się ukryć, że metody diagnostyczne ilościowe w przeciwieństwie do testów klinicznych dostarczają obiektywnych danych liczbowych, pozwalają na dokładną analizę parametrów równowagi z zastosowaniem rozmaitych rozwiązań technologicznych. Do pomiaru parametrów równowagi i stabilności posturalnej wykorzystywane są platformy stabilometryczne, pozwalające na prostą, szybką i wiarygodną ocenę pacjenta w pozycji stojącej. Wiele doniesień medycznych coraz częściej skupia się na ocenie równowagi seniorów, a uzyskane dane liczbowe pozwalają na opracowywanie programów usprawniających oraz analizę ich rezultatów [9-10]

W niniejszej pracy wykazano, iż badana grupa charakteryzowała się zaburzeniami stabilności posturalnej i równowagi podczas spokojnego stania. Ze względu na wielochorobowość pensjonariuszy rzeszowskiego Domu Pomocy Społecznej do badania przy pomocy platformy stabilometrycznej Cosmogamma zakwalifikowanych zostało jedynie 27 seniorów, którzy wykazywali zdolność samodzielnego utrzymania pozycji stojącej.

Badanie problemu niestabilności posturalnej, a tym samym zagrożeń upadkami u seniorów domów opieki spotecznej jest szczególnie istotne w kontekście obecnych prognoz demograficznych wskazujących na szybkie starzenie się społeczeństw [13]. U osób starszych wraz z wiekiem wzrasta liczba występowania upadków prowadzących niejednokrotnie do poważnych następstw zdrowotnych i społecznych [14]. Ma to związek z występowaniem różnych czynników ryzyka, z których większość jest powiązana ze zmianami inwolucyjnymi, typowymi dla procesu starzenia się organizmu ludzkiego.

W wyniku przeprowadzonych badań stwierdzono, że wiek jest czynnikiem który wpływa na zwiększenie długość ścieżki pokonywanej przez środek nacisku stóp na platformę oraz zwiększenie wychyleń bocznych i przednio-tylnych podczas spokojnego stania.

Platforma stabilometryczna jest wymiernym narzędziem badawczym, za pomocą którego mogą być bada- ni pacjenci z różnymi jednostkami chorobowymi. Kłoda i współautorzy wykazali dodatnią korelację pomiędzy wiekiem, a parametrami równowagi ocenionymi na platformie stabilometrycznej, zarówno w próbie z kontrolą, jak i bez kontroli wzroku [15].

Wyniki otrzymane $w$ niniejszej pracy dowodzą, że szczególną rolę w utrzymaniu równowagi odgrywa kontrola wzroku. W staniu swobodnym informacja wzrokowa działa silnie stabilizująco na utrzymanie pozycji, a chwilowe wyłącznie kontroli wzroku powoduje zmianę ilości i amplitudy wychyleń. Podobne badania zostały przeprowadzone wśród grupy chorych we wczesnym okresie choroby Parkinsona. Stwierdzono wówczas, że podczas zamknięcia oczu przez pacjentów, średnie wychylenia boczne COP zwiększyły się [16]

W procesie utrzymania równowagi istotnym czynnikiem wydaje się być element treningu. Przeprowadzone w pracy próby o oczach zamkniętych wykazały nieznaczną poprawę w przypadku powtórnego badania na platformie po upływie 15 minut. Podobne obserwacje opisał Wilczyński, który badał reakcje równoważne, skupiając się głownie na młodzieży ze skoliozą $[17,18]$ Stwierdził, że istnieje potrzeba stosowania w reedukacji posturalnej ćwiczeń doskonalących równowagę przez biofeedback z wykorzystaniem platformach posturograficznych.

Badania stabilności posturalnej, a przy tym ryzyka upadków, za pomocą platformy stabilometrycznej Cosmogamma by Emildue pozwalają uzyskać obiektywne dane liczbowe. Wyniki takie mogą być wykorzystane do monitorowania wpływu rehabilitacji czy aktywności fizycznej na równowagę statyczną ciała. Jednakże próba 27 osób wydaje się zbyt mała, aby wyciągać wnioski dotyczące niezawodności tejże metody. Dlatego też autorzy niniejszych badań prowadzą dalsze, szersze obserwacje obejmujące większą grupę osób po 65 roku życia.

\section{Wnioski}

1. Wraz z wiekiem spada zdolność utrzymania równowagi w pozycji stojącej.

2. Płeć nie ma wpływu na wartości obserwowanych parametrów, a tym samym nie ma istotnego znaczenia w ocenie poziomu równowagi.

3. Wyłączenie kontroli wzroku wpływa niekorzystnie na stabilność posturalną.

4. Istotnym czynnikiem wpływającym na poprawę zdolności utrzymywania równowagi jest element treningu. 


\section{Oświadczenia}

Oświadczenie dotyczące konfliktu interesów

Autorzy deklarują brak konfliktu interesów.

\section{Źródła finansowania}

Autorzy deklarują brak źródeł finansowania.

\section{Piśmiennictwo}

1. El-Khoury F, Cassou B, Charles MA, Dargent-Molina P. The effect of fall prevention exercise programmes on fall induced injuries in community dwelling older adults: systematic review and meta-analysis of randomised controlled trials. BMJ 2013:347: 1-13.

2. Granacher U, Gollhofer A, Hortobágyi T, Kressig RW, Muehlbauer T. The importance of trunk muscle strength for balance, functional performance, and fall prevention in seniors: a systematic review. Sports Med 2013;43(7):627-641.

3. Baloh RW, Ying SH, Jacobson KM. A longitudinal study of gait and balance dysfunction in normal older people. Arch. Neurol. 2003; 60: 835-839.

4. Błaszczyk JW, Czerwosz L. Stabilność posturalna w procesie starzenia. Gerontologia Polska, 2005, 13, 1, 25-26.

5. Horak FB. Postural orientation and equilibrium; what do we reed to know abort neural control of balance to prevent falls?. Age Aging, 2006, 7-11.

6. Bruyere O, Wuidart MA, Di Palma E, Gourlay M. Controlled Whole Body Vibration to Decrease Fall Risk and Improve Health-Related Quality of Life of Nursing Home Residents. Arch. Phys. Med. Rehabil., 2005, 86, 303-307.

7. Finlayson MC, Petersom EW, Cho CC. Risk factors for falling among people aged 45 to 90 Years with Multiple Sclerosis. Arch. Phys. Med. Rehabil., 2006, 87, 1274-1279.

8. Clinical practice guideline for the assessment and prevention of falls In older people. Guidelines commissioned by the $\mathrm{Na}$ tional Institute for Clinical Exellence (NICE). Royal College of Nursing, 2004.

9. Kuo AD, Speers RA, Peterka RJ, Horak FB. Effect of altered sensory condition on multivariate descriptors of human postural sway. Exp. Brain Res. 1994; 122: 185-195.

10. Brooke-Wavell K, Perrett LK, Howarth PA, Haslam RA. Influence of the visual environement on the postural stability in healthy older women. Gerontology 2002; 48: 293-297.
11. Skalska A, Ocetkiewicz T, Żak M, Grodzicki T. The influence of age on the parameters of the postural control measured by the computer balance platform. New Medicine 2004; 7:12-19.

12. Okada S, Hirakawa K, Takada Y, Kinoshit H. Relationship between fear of falling and balancing ability during abrupt deceleration in aged women having similar habitual physical activities. Eur. J. Appl. Physiol. 2001; 85: 501-506.

13. Ostrowska B, Giemza Cz, Demczuk-Włodarczyk E, Adamska M. Ocena równowagi i chodu u starszych osób pensjonariuszy domu opieki społecznej. Fizjoterapia, 2010, 18, 4, 40-48.

14. Szot P, Golec J, Szczygieł E. Przegląd wybranych testów funkcjonalnych, stosowanych w ocenie ryzyka upadków u osób starszych. Gerontologia Polska, 2008; 16, 1.

15. Kłoda M, Brzuszkiewicz-Kuźmicka G, Grzegorzewska J, Białoszewski D. Ocena stabilności posturalnej pacjentów z chorobą Parkinsona. Post Rehabil 2013;(1):5-11.

16. Panyakaew P, Anan C, Bhidayasiri R. Visual deprivation elicits subclinical postural inflexibilities in early Parkinson/s disease. Journal of the Neurological Sciences, volume 349, Issues 1-2, Pages 214-219.

17. Wilczyński J. Reakcje równoważne na przykładzie prędkości przednio-tylnej posturogramu u dziewcząt i chłopców w wieku 12-15 lat. Studia Medyczne 2010; 20:13-17

18. Wilczyński J. Boczne skrzywienie kręgosłupa a długość ścieżki posturogramu u dziewcząt i chłopców w wieku 12-15 lat. Ortop. 2012; 1: 126-134

Zaakceptowano do edycji: 20.08 .19 Zaakceptowano do publikacji: 26.09.19

Adres do korespondencji:

Marzena Mańdziuk

ul. Jabłońskiego $7 / 28$

35-068 Rzeszów

tel. 530869888

e-mail: mmandziuk@wsiz.rzeszow.pl 